\title{
The effects of flooding on survivorship in overwintering larvae of the large copper butterfly Lycaena dispar batavus (Lepidoptera: Lycaenidae), and its possible implications for restoration management
}

\author{
Colin N. NICHOLLS ${ }^{1 *}$ and ANDREw S. PULLIN ${ }^{2}$ \\ ${ }^{1}$ Department of Cell and Developmental Biology, John Innes Centre, Colney Lane, Norwich, Norfolk, NR4 7UH, UK \\ ${ }^{2}$ School of Biosciences, University of Birmingham, Edgbaston, Birmingham, B15 2TT, UK
}

Keywords. Butterfly, Lycaena dispar batavus, larvae, overwintering, flooding, submergence, restoration, Broadland

\begin{abstract}
Previous work suggests that submergence of Lycaena dispar larvae during overwintering may play a significant role in this butterfly's population dynamics. Since potential re-introduction sites in eastern England are prone to regular seasonal flooding, we further studied the species' submergence tolerance with a view to formulating management protocols conducive to larval survivorship under periodic flood conditions. Simulated flooding regimes using captive-reared larvae showed that enforced submergence has a twofold effect: firstly, a direct increase in mortality after 28 days under water and, secondly, a longer term, post-diapause increase in mortality; manifest either as an inability of larvae to resume feeding, or a failure to complete development. Additionally, there was a marked difference in the response of "early" and "late" diapause larvae; the latter generally succumbing after shorter periods under water, and suffering higher total mortalities. Behavioural investigations suggest that, if afforded the opportunity, diapausing larvae can evade submergence by climbing onto the exposed sections of partially flooded host plants. Significantly, survival on partially flooded plants was found to be comparable to that on unflooded controls. Further re-introductions of $L$. dispar in the U.K. will probably necessitate a direct translocation of wild Dutch stock. As the flood tolerance of this source population remains largely undetermined, and given that re-introduction site hydrology will be generally unamenable to conservation-oriented manipulation, it is recommended that restoration management be directed towards creating structural diversity in the vegetation of overwintering habitats, thereby providing potential "flood refugia" for hibernating larvae.
\end{abstract}

\section{INTRODUCTION}

Two specimens collected during the $19^{\text {th }}$ century from the Broadland region of eastern England - one labelled "Ranworth, 1860" the other "Woodbastwick, 1864" may well represent the last reliable evidence of the (now extinct) English race of the Large Copper butterfly, Lycaena dispar dispar Haworth (Irwin, 1984). The demise of $L$. $d$. dispar in Broadland seems almost certain to have been driven by the extensive loss of former fenland habitats (through successional change), hastened by the abandonment of traditional management practices (Pullin et al., 1995). In contrast, elsewhere within its historic range large scale drainage, and the subsequent reclamation for agriculture, was probably the principal factor contributing to the butterfly's decline (Duffey, 1968). Though still extant throughout much of mainland Europe, eastwards across temperate Asia to Korea, other subspecies of the Large Copper have undergone marked declines in the wake of wetland degradation and fragmentation (Pullin et al. 1998). In the Netherlands, for example, the endemic subspecies batavus has suffered considerable losses, to the extent that it may now be represented by just two self-sustaining populations - inhabiting the Weerribben and Wieden National Parks (Tax, 1989; Oostermeijer, 1996; G. Padding, pers. comm.). Currently listed as "endangered" in the IUCN Red List of threatened animals (IUCN, 1990), L. dispar's imperilled status also merits its scheduling under the 1979 Convention on the Conservation of European Wildlife and Natural Habitats (Bern Convention) and its inclusion in Annexes II and IV of the 1992 European Community Habitats Directive. In addition, since 1991, L. dispar has featured as one of the target invertebrates under the umbrella of English Nature's Species Recovery Programme, and this distinction has fostered a renewed impetus in researching the butterfly's ecology and habitat requirements (Pullin, 1997).

In its native wetland habitat, $L$. d. batavus is univoltine and host-specific, ovipositing on a single larval food plant, the Great Water Dock Rumex hydrolapathum Hudson. Eggs hatch in August and larvae feed for approximately four weeks, prior to entering winter diapause as second instars. Diapause is characterized by a cessation of feeding, followed by migration to the base of the host plant. Here, the cryptic larvae seek out senescent Rumex leaves that will serve as winter hibernacula. Subject to local seasonal climate, dormancy termination and resumption of feeding occur between late March and early May. Larvae subsequently undergo a further two moults prior to pupation in June. Adults are on the wing from late June through to late August, peaking in abundance during the latter half of July (Pullin et al., 1998).

Throughout the present century considerable conservation effort has been expended in the shape of a succession

\footnotetext{
* Corresponding author. E-mail: colin.nicholls@BBSRC.ac.uk
} 
of attempts to re-introduce $L$. dispar to the UK (Duffey, 1968; Webb \& Pullin, 1996). To date, none of these have resulted in establishment of a self-sustaining population. Given the prominent role wetland drainage is traditionally presumed to have played in the butterfly's historical decline, it is perhaps somewhat ironic that several reestablishment attempts have been thwarted, not so much by a deficiency of water, but by its unseasonal excess (Ellis, 1951, 1965; Duffey, 1968). As an acknowledged wetland specialist, it seems not unreasonable to expect $L$. dispar to exhibit traits adapting it both physiologically and behaviourally to a seasonally flooded fenland habitat. Indeed, a longstanding consensus held that overwintering larvae displayed tolerably good resistance to periodic submergence (Anon, 1929; Purefoy, 1929; Duffey, 1968). More recent research has, however, challenged this assumption. In a comparative field ecology study, Webb and Pullin (1996) reported mortality during the overwintering stage to be markedly higher at a flood-prone English site than at an otherwise comparable non-flooding Dutch site. This circumstantial evidence for the detrimental affects of flooding gained support from complementary laboratory investigations (Webb \& Pullin, 1998) in which it was shown that episodes of inundation, if sufficiently prolonged, could significantly increase the risk of larval death during hibernation. Moreover, it became evident that the incidence of mortality recorded immediately post-submergence is frequently not a sufficient predictor of the eventual flood-induced fatalities (Webb \& Pullin, 1998). This latter observation suggests a twofold submergence response, which can be defined as acute and chronic. The former represents immediate mortality, ascribed to the submergence event per se, where larvae succumb whilst still under water (e.g. from anoxia). Chronic symptoms are manifest over a longer timescale in, for example, an inability to resume feeding, a failure to complete development or, conceivably, more subtle effects, such as a perturbation of the phenological synchrony evolved between the insect and its host plant (cf. Chippendale, 1982; Tauber et al., 1986; Danks, 1987; Woiwod, 1997). Post-submergence chronic effects, analogous to that seen in $L$. dispar, have also been described in other wetland invertebrates, notably the larch sawfly Pristophora erichsonii Hartig (Lejeune \& Filuk, 1947; Lejeune et al., 1955), and the large heath butterfly Coenonympha tullia Muller (Joy \& Pullin, 1997, 1999).

As some of the potential re-introduction sites in Broadland are prone to seasonal flooding (Giller \& Wheeler, 1986; George, 1992), further investigations of the capacity of larval populations to withstand protracted inundation, allied to an evaluation of possible floodmitigation measures, are needed prior to undertaking any further re-establishment attempts.

In striving to experimentally simulate natural field conditions, an additional layer of complexity arises from the growth habit of the food plant itself. $R$. hydrolapathum generally flowers during its second year of growth (Duffey, 1971) and, following autumnal senescence, the tall (up to $2 \mathrm{~m}$ ) flower stalk (typically bearing a few withered bract leaves) often persists in situ throughout the winter months. In most circumstances a substantial proportion of the senescent stem would be expected to protrude above the level of all but the most exceptional of floods. The potential "flood-refuge" value of these inflorescent growths to overwintering larvae has been commented on in the past (e.g. Purefoy, 1929; Duffey, 1968; Duffey \& Mason, 1970; Tinning, 1975), as has the considerable movement of which larvae appear capable, during what is normally considered a period of overwintering dormancy (Duffey, 1968; Tinning, 1975). Given the potential impediment of flooding to L. dispar re-establishment, the present study was conceived with the following aims:

(1) To assess the impact of varying periods of enforced submergence on overwintering larvae, in the context of both short and long-term survival.

(2) To assess the impact of time of flooding, by comparing the responses of early and late diapause larvae to submergence.

(3) To investigate the behavioural responses of larvae under conditions of partial - as opposed to complete food plant submergence.

(4) To consider management options that might enhance the viability of field populations under flood conditions.

\section{METHODS}

All larvae used in the investigation were derived from a captive-reared colony of $L$. d. batavus maintained at Woodwalton Fen National Nature Reserve, Cambridgeshire, U.K. since 1970, and transferred to the University of Birmingham for the purposes of this study. The Woodwalton colony can itself be traced back to a small founding population of Dutch batavus, originally released onto the fen in 1927 (Duffey, 1968).

\section{The impact of varying durations of submergence on larval survival}

Assessment of flood tolerance under conditions of enforced submergence incorporated a parallel set of experiments in which the response of both early and late diapause larvae (see below) were examined. Prior to the imposition of treatment conditions, larvae were subjected to a preliminary pre-conditioning or diapause-induction phase devised (from previous studies) to take them through to the desired stage of development (Webb \& Pullin, 1998). Larvae, raised from egg eclosion to the $2^{\text {nd }}$ instar stage under short day illumination (9L : 15D) at room temperature $\left(\sim 20^{\circ} \mathrm{C}\right)$, were transferred to senescent leaves of $R$. hydrolapathum (10 larvae per leaf), which would serve as overwintering hibernacula. Leaves were placed into filter paperlined perspex entomological boxes, and retained within controlled environment cabinets, running on a photoperiod/ temperature regime $\left(9 \mathrm{~L}: 15 \mathrm{D}, 5^{\circ} \mathrm{C}\right)$ designed to simulate overwintering conditions. Early diapause pre-conditioning was terminated after a period of four weeks, by which time it is assumed larvae have attained full metabolic suppression (e.g. Tauber \& Tauber, 1976; Tauber et al., 1986; Danks, 1987). Late diapause individuals were retained under induction conditions for a further 16 weeks. This period was calculated to take them through to a stage of development equivalent to that of imminent dormancy termination in field populations when metabolism will be more active. To achieve synchrony in the subsequent submergence treatments, late diapause preconditioning was commenced 16 weeks in advance of that for early diapause larvae. 
TABLE 1. Estimates of the capacity of Lycaena dispar batavus to survive submergence during overwintering. Data presented are from probit analysis of larval survival ( $95 \%$ fiducial limits are shown in parentheses).

\begin{tabular}{lccc}
\hline & \multicolumn{3}{c}{ Submergence time (days) } \\
\cline { 2 - 4 } & LT $10^{\mathrm{a}}$ & LT 50 & LT 90 \\
\hline Early diapause & & & \\
$\quad$ immediate response & $44.4(16.4-61.3)$ & $90.8(66.6-162.8)$ & $184.4(119.8-978.0)$ \\
$\quad$ resumption of feeding & $25.8(8.5-35.2)$ & $36.9(22.4-46.6)$ & $53.0(42.1-89.5)$ \\
Late diapause & & & $56.4(37.6-111.8)$ \\
$\quad$ immediate response & $6.7(2.99-10.5)$ & $19.4(12.9-28.1)$ & $47.4(31.4-91.2)$ \\
$\quad$ resumption of feeding & $3.5(1.7-5.4)$ & $12.9(8.9-18.2)$ & \\
\hline
\end{tabular}

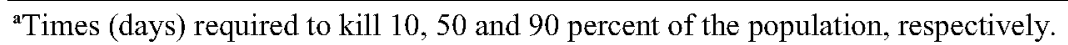

Following pre-conditioning, leaf hibernacula harbouring diapause larvae were pinned to short cane supports, and these were inserted amongst the withered foliage of potted senescent Rumex plants (one hibernacula per plant). Host plants were enmeshed with muslin sleeves to counter any tendency for larvae to wander, and then placed into a large plastic water tank. Muslin-filtered lake water ( $\mathrm{pH} 6.5$ ) was progressively added to the tank to a final depth that ensured all host plant material was completely immersed. Temperature and illumination were held constant $\left(9 \mathrm{~L}: 15 \mathrm{D}, 5^{\circ} \mathrm{C}\right)$ for the duration of the experiment. Larvae were assessed for their ability to withstand submergence over five treatment periods $(3,7,28,56,112$ days $)$. These were selected as a range of times culminating in an interval representing a full winter (which has been recorded in some potential re-introduction sites) and additionally allowed statistical estimation of a lethal time at which $50 \%$ of the population perish $\left(\mathbf{L T}_{50}\right)$. Submergence treatments and an unflooded control were run in duplicate, such that totals of 20 larvae were subjected to each period of immersion. After flooding treatments, designated plants were carefully withdrawn from the tank, and plants allowed to drain for 24 hours. An initial assessment of larval viability was undertaken with the aid of a low power binocular microscope. Those larvae showing either signs of movement, or no outward evidence of mortality (e.g. waterlogging, fungal growth) were recorded alive at this stage. Surviving larvae, retained on their leaf hibernacula, were then either returned to normal overwintering conditions $\left(9 \mathrm{~L}: 15 \mathrm{D}, 5^{\circ} \mathrm{C}\right)$ until diapause termination (early diapause) or, to simulate a late diapause situation experienced by field populations, provisioned with fresh growths of Rumex, and exposed to a regime of increasing photoperiod and temperature (increments of $30 \mathrm{~min}$ and $2^{\circ} \mathrm{C}$ per day, over a period of 8 days) (late diapause). Thereafter, larval viability was monitored at regular intervals to ascertain any delayed effects of submergence on long-term survival.

\section{Behaviour and survival in response to partial submergence of host plant}

Over two consecutive years (1997 and 1998) a complementary investigation was undertaken to examine the behavioural response of larvae to submergence. Early diapause larvae (preconditioned as described above) were assigned to one of two submergence treatments - either partial or total. For each treatment, 10 larvae were transferred to the leaves of individual semi-senescent pot-grown Rumex plants. Plants, bearing larvae, were placed within 25 litre glass tanks to which water was subsequently added to a level, that either completely immersed plants (total submergence treatment), or left approximately one third of the foliage protruding above the water surface (partial submergence treatment). In the case of partial submergence, five of the ten larvae (marked with a small spot of white correction fluid) were positioned so that initially they fell below the water- line, whereas the remaining five were placed on leaves projecting above the waterline. Unflooded control plants and larvae were retained within additional "dry" tanks. Owing to the small number of larvae available in 1997, treatment duplication was only possible during the second year of the investigation. Thus, for each flooding regime, the fate of 10 and 20 larvae were followed in the first and second year, respectively. The experiment was conducted in an external poly tunnel which, though affording protection from wind and rain, was otherwise subject to the ambient seasonal climate. Observations of larval position and movement, and records of maximum and minimum temperature, were made daily for 45 days $(22 / 10 / 97$ to $5 / 12 / 97)$ and 58 days $(14 / 10 / 98$ to $11 / 12 / 98)$. Subsequently, plants were withdrawn from the tanks, and an initial estimate of larval survival was undertaken. Thereafter, plants were retained within the poly tunnel for a further 16 weeks prior to assessing final overwintering mortalities.

\section{RESULTS}

\section{The impact of varying durations of submergence on larval survival}

The pattern of larval mortality under conditions of enforced submergence was found to be determined by two aspects of the flooding regime: its duration and its timing in relation to the stage of larval development. Statistical evaluation of survivorship data, using a G-test for frequency analysis (cf. Fowler \& Cohen, 1990), revealed both highly significant associations between treatment (length of submergence) and survival (early diapause $G=$ 57.16, $d f=4, p<0.001$; late diapause $G=131.81, d f=4$, $p<0.001$ ), and a highly significant difference in the responses of early and late diapause larvae to the treatments (early vs. late diapause $G=29.58$, $d f=5, p<$ 0.001). Comparison with controls indicates that, for early diapause larvae, periods of enforced submergence, up to at least 28 days, effect no increase in either immediate or long-term larval mortality. But, although short-term survival remains unaffected after $\mathbf{5 6}$ days under water, it is at this stage that the delayed repercussions of submergence become evident. Only a single larva exposed to the 56 day treatment successfully resumed feeding and completed development. After 112 days submergence, immediate survivorship had undergone a marked decline to $30 \%$, and of those larvae still alive at this stage, all had perished by the termination of diapause. In contrast, and consistent with a priori assumptions (see discussion), the detrimental effects of enforced submergence on late dia- 

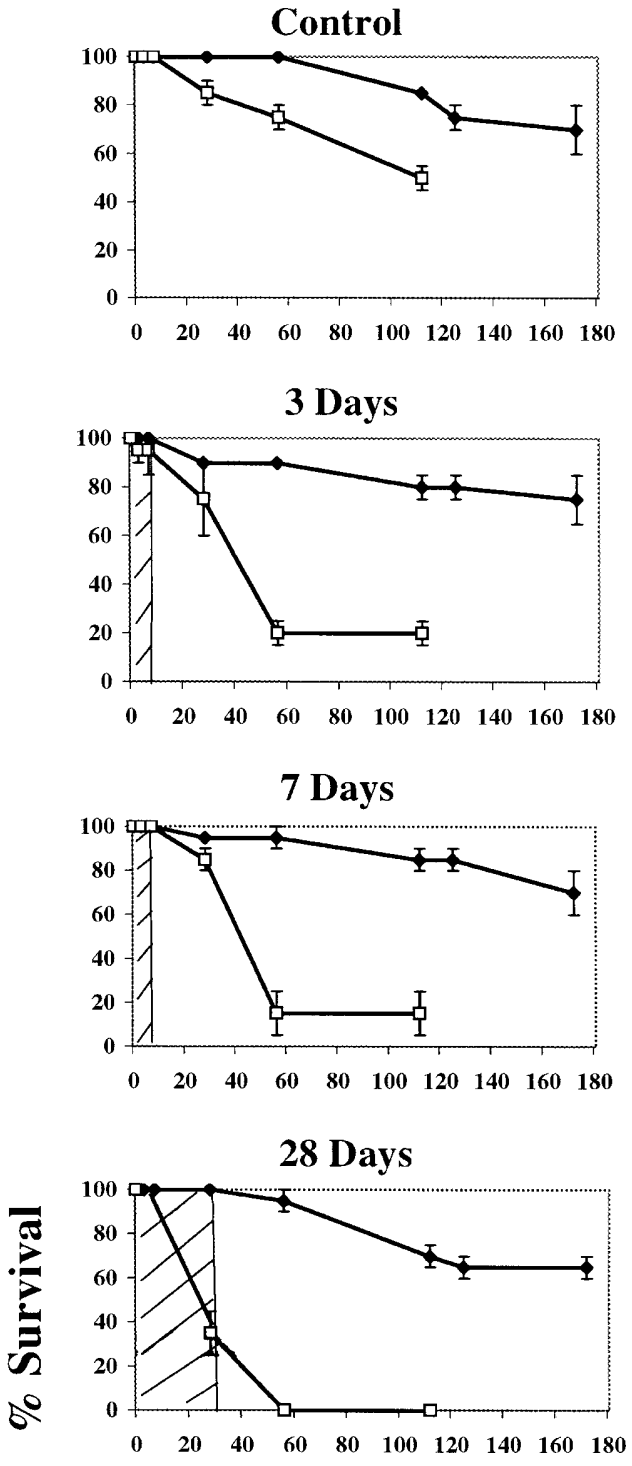

56 Days

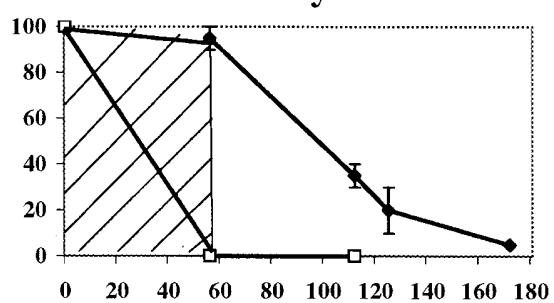

112 Days

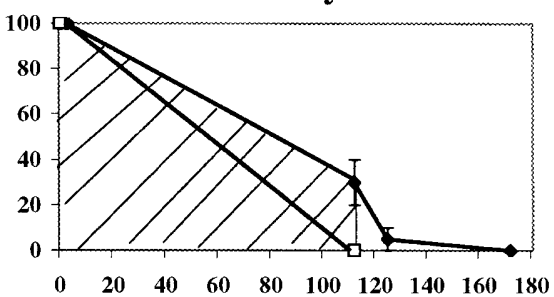

Days after start of experiment

Fig. 1. The effects of varying periods of submergence on early $(\bullet)$ and late $(\square)$ diapause $L$. d. batavus larvae. Shaded areas represent the time larvae spent under water. pause larvae were observed over considerably shorter durations of exposure. Recorded mortalities after 28 and 56 days were $65 \%$ and $100 \%$, respectively. Control mortality rates over the same time periods were $15 \%$ and $25 \%$. Even relatively brief periods of immersion ( 3 and 7 days), although having a negligible effect on immediate survival, caused substantial mortality in the longer term (Fig. 1). A probit analysis (Finney, 1971) of the survivorship data (Table 1) gave estimated $\mathrm{LT}_{50}$ values (the period of submergence required to kill $50 \%$ of the population) of 90.8 and 19.4 days, for early and late diapause larvae, respectively. Corresponding values based upon the numbers of larvae that actually recommenced feeding were 36.9 and 12.9 days.

\section{Behaviour and survival in response to partial submergence}

In circumstances where larvae were given an opportunity to evade submergence, there was a certain degree of bi-directional migration across the water barrier. Correlation analysis using the Spearman rank correlation test, revealed a significant relationship between larval position and mean daily temperature (Spearman rank correlation coefficient : $1997, r_{s}=0.694, n=25, r_{\text {scrit }}=0.526, p<$ $\left.0.01 ; 1998, r_{s}=0.759, n=51, r_{\text {scrit }}=0.368, p<0.01\right)$. Thus, a sufficient depression in temperature might induce larvae to seek shelter beneath the waterline, whereas at elevated temperatures there could be a tendency for individuals to climb onto exposed portions of the host plant. Whereas a response to fluctuating temperatures remains highly plausible, this does not of course rule out the possibility of partial, or indeed exclusive, reaction to additional unmonitored physical variables (e.g. variations in light level). Furthermore, since individual larvae could not be reliably identified, it was not always possible to ascertain which larvae were actually moving across the water barrier. Nonetheless, given that survivorship on partially submerged plants (recorded at the conclusion of the experiment) was equal to that on control 'dry' plants in 1997: 4 larvae (40\% survival), and only marginally less in 1998: control $=7$ larvae ( $35 \%$ survival), partially submerged $=6$ larvae $(30 \%$ survival), whereas survival under conditions of complete submergence was zero in both years, it is evident that an opportunity for larvae to escape flooding could have important implications with respect to the vegetation management of overwintering habitats (Table 2). This contention is borne out by complementary observations made under field conditions, both in the UK and the Netherlands (Nicholls, 2000).

\section{DISCUSSION}

An evaluation of flood tolerance in Lycaena dispar should ideally take into consideration not only the duration of the submergence period itself, but also its timing relative to the stage of larval development. Although the precise mechanistics underlying submergence-induced larval mortality remains to be conclusively resolved - and past workers have sometimes presented conflicting accounts of larval survival under flood conditions (Anon, 1929; Purefoy, 1929; Duffey, 1968, 1977; Webb \& 
TABLE 2. Survivorship of early diapause $L$. dispar larvae overwintered under conditions of total and partial submergence. Numbers refer to the number of larvae subjected to each treatment and those recorded as alive at the termination of diapause.

\begin{tabular}{|c|c|c|c|c|}
\hline \multirow{3}{*}{$\begin{array}{l}\text { Submer- } \\
\text { gence } \\
\text { treatment }\end{array}$} & \multicolumn{4}{|c|}{ Larval survival } \\
\hline & \multicolumn{2}{|c|}{1997} & \multicolumn{2}{|c|}{1998} \\
\hline & $\begin{array}{c}\text { Pre- } \\
\text { submergence }\end{array}$ & $\begin{array}{c}\text { Post- } \\
\text { submergence }\end{array}$ & $\begin{array}{c}\text { Pre- } \\
\text { submergence }\end{array}$ & $\begin{array}{c}\text { Post- } \\
\text { submergence }\end{array}$ \\
\hline Total & 10 & 0 & 20 & 0 \\
\hline Partial & 10 & 0 & 20 & 6 \\
\hline Control & 10 & 4 & 20 & 7 \\
\hline
\end{tabular}

Pullin, 1998) - the accumulating evidence strongly indicates that prolonged flooding, particularly if coincidental with a physiologically vulnerable stage of larval development, can have potentially profound repercussions for the population dynamics of this species. With respect to submergence tolerance in early diapause larvae, the concordance that exists between the earlier observations of Webb \& Pullin (1998) and those made during the present work, gives some grounds for invoking the concept of a "flood tolerance threshold" in $L$. dispar: an innate adaptation that defines a maximum length of time the majority of larvae are capable of withstanding uninterrupted submergence without detriment. Both studies would appear to suggest that immersion of early-diapausing larvae, for at least one month, has a negligible effect on larval viability, both in the short and longer terms. But for periods of submersion exceeding the putative threshold, a combination of acute and chronic effects can result in a substantive cumulative mortality. Beyond the $56^{\text {th }}$ day under water few individuals retain the capacity to complete normal larval development. Further experiments in which, for example, early diapause larvae are exposed to an expanded range of submergence treatments, spanning the 28 to 56 day interval, would doubtless go some way in pinpointing this critical boundary. Determination of a comparable threshold effect for late diapause larvae is liable to be more problematic owing to the greater possibility for asynchronous development at this stage (Danks, 1987). Nevertheless, towards the end of normal diapause, resource-depleted larvae would predictably be acutely vulnerable to the debilitating consequences of prolonged submergence. The data presented here, indicating a markedly greater susceptibility in late diapause, with periods of less than 28 days causing over $50 \%$ mortality, are consistent with this premise. Furthermore, the laboratory results also find support in several documented field observations. In 1951, for example, two years after the successful introduction of subspecies batavus to a site in the Yare Valley, Norfolk, post-diapause larval emergence coincided with a period of extensive spring tidal flooding, and this was thought to be instrumental in wiping out the established colony. Similarly, at Woodwalton Fen in 1966, flood conditions persisted well into the month of
May, delaying larval emergence, and as a consequence led to poor survival (Duffey, 1968).

Clearly, a degree of caution needs to be exercised when invoking physiological concepts like a 'flood tolerance threshold' in the context of field populations. Tenuous relationships between the field and laboratory will inevitably be confounded by habitat features and environmental exigencies that are largely unamenable to ex situ replication. Irregularities in fenland relief, for instance, tend to generate a mosaic of spatially-dispersed microtopographic and microclimatic situations in which $R$. hydrolapathum grows. This spatial matrix may in turn give rise to a marked temporal variability in the degree and the length to which food plants are subject to flooding. Rumex plants growing along watercourses may, for example, be either partially or totally submerged for periods exceeding that of the longest treatment time (112 days) imposed during the current investigations. The putative avoidance of these "riparian" Rumex by ovipositing females (Duffey, 1968), and the suggested preference for those plants growing on the slightly raised substratum of mixed herbaceous fen, could arguably be interpreted as an adaptive strategy designed to evade the worst excesses of unpredictable inundation. However, recent research on host plant selection (Pullin, 1997; Webb \& Pullin, 2000) has found little evidence to substantiate this supposition.

Results from the behavioural experiments suggest that larval movement is of frequent occurrence during overwintering and is at least partially temperature dependent. This conclusion finds support in Duffey's (1968) observation that diapausing larvae in captivity became active during the winter if the air temperature rose above $7^{\circ} \mathrm{C}$. Comparable manoeuvrability has been noted in overwintering larvae of C. tullia (Joy \& Pullin, 1997, 1999), which are also able to feed when conditions are sufficiently mild - an option which, given the annual senescence of Rumex, is generally not available to overwintering $L$. dispar.

A propensity for diapausing larvae to migrate to elevated "flood refuges" (whether temperature-induced or not) could go some way in reconciling the disparate opinions previously expressed on flood tolerance in $L$. dispar. Assessment of larval viability by earlier workers, most notably Purefoy (1929) and Duffey (1968), was based largely upon observations made under conditions of incomplete submergence. Viewed from this perspective, Duffey's ostensibly paradoxical observation, that survival on "flooded" plants exceeded that recorded on controls, is perhaps more readily explicable. Of the 45 larvae surviving his flooding regime, 35 were found to be located on the upper, emergent extremities of the host plants. Subsequent work on submergence tolerance in $L$. dispar indeed led Duffey to a re-evaluation of his initial findings (Duffey, 1977). If results obtained from the current behavioural research are taken to be broadly representative of behavioural patterns in the field then, implicitly, there may be little difference between partially flooded 
and unsubmerged host plants in terms of potential overwinter larval survival.

A further important question arising from recent work on flood tolerance in L. dispar (cf. Webb \& Pullin, 1998), and one that has a significant bearing on the proposed reintroduction of the butterfly to the UK, concerns the genetic fitness of the larval population used. The current research population is derived from a colony reared under captive conditions at Woodwalton Fen since 1970. This population was in turn descended from individuals taken from an independent captive population established during the early 1960 s from wild Woodwalton stock. The latter was inaugurated as an insurance policy against extinction of the butterfly on the fen (a fate which indeed was to befall the Woodwalton population following unprecedented summer flooding in 1968). Sustained over successive generations in novel ex-situ environments, small populations may undergo evolutionary changes that contribute to an erosion of genetic variability and individuals may progressively develop traits which, although adaptive under artificial confined situations, render them less well adapted to survival in the wild (Frankham, 1995). Adaptation of invertebrate populations to captive environments has been widely documented (e.g., Ayala, 1965; Briscoe et al., 1992; Frankham \& Loebel, 1992; Latter \& Mulley, 1995) and, given strong directional selection, shown in some instances to occur relatively rapidly (Miyatake \& Yamagishi, 1999; Lewis \& Thomas, 2001). Although lacking critical evidence, a comparative study of wild and captive bred $L$. dispar has led us to argue previously (Nicholls \& Pullin, 2000) that these two populations may now have diverged genetically as a consequence of experiencing contrasting genetic milieus. In this context, a potentially significant early observation was that made during the winter of 1927-28, shortly following the original introduction of subspecies batavus to Woodwalton Fen. Hibernating larvae were at this time subjected to 60 days continuous flooding, without apparently a marked impact on their subsequent survival (Purefoy, 1929; Riley, 1929). This circumstantial evidence suggests a superior flood tolerance prior to the start of the captive rearing programme and, together with our more recent research, leads us to speculate that prolonged $e x$ situ propagation may in some respects have now compromised flood tolerance in the captive stock. At present the ability of wild populations of $L$. dispar to survive extended periods under water remains undetermined. Regrettably, owing to the endangered status of the butterfly in its native habitat, a potentially definitive comparative study of flood tolerance in captive and wild populations cannot at present be justified. Nonetheless, given the suspected "genetic inferiority" of the captivereared butterflies, it now seems inevitable that any future re-introductions will necessitate a direct translocation of individuals from the wild Dutch population.

\section{Implications for habitat management}

Implications for conservation management have to be viewed with some caution as we cannot be sure if wild populations will be more or less susceptible to flooding than the captive bred population used in this study. Despite this, the results of the submergence experiments do highlight the necessity to include an appraisal of local hydrology (particularly the timing, frequency and magnitude of flood episodes) as an integral element in the assessment of potential re-introduction sites. The current restoration programme for $L$. dispar in the UK is focusing primarily on the floodplain fens of Broadland; now probably the only region within the historical range of subspecies dispar retaining sufficient habitat to support a viable population(s) of this characteristically dispersive, low density butterfly (Pullin, 1997). Significantly, however, from a restoration viewpoint, many of the Broadland fens experience a considerable seasonal flux in water levels (amplitude $>50 \mathrm{~cm}$ ) and therefore pose potential problems for remedial management (Giller \& Wheeler, 1986). The broader conservation relevance of our findings can perhaps be put into perspective by reference to a recent series of experimental releases in Broadland (Nicholls \& Pullin, 2000). These showed significantly greater larval survivorship over the relatively dry winter of 1996/1997 compared with the winters of $1995 / 1996$ and $1997 / 1998$, during both of which prolonged flooding occurred.

A stated objective of the ongoing Fen Management Strategy for the Broadland region (Broads Authority, 1997) is the reinstatement of a natural hydrological regime to the fen drainage system. As a consequence, any water level manipulation targeted specifically for the benefit of $L$. dispar, although technically feasible on a limited scale, is unlikely to constitute an exclusive longterm conservation option. Management of the vegetation communities, of which the butterfly's food plant $R$. hydrolapathum is a typical associate (notably the Peucedano - Phragmitetum herbaceous fen community (Wheeler, 1978)) would seem to offer a more practical and sustainable solution. Essential as vegetation management will almost inevitably be (in the short-term at least), a detailed understanding of site hydrology, and predicting how this might change with time, will, nevertheless, remain integral to any future remedial management. Given predictions emanating from some of the current climatic models, there seems a strong likelihood that both the frequency and magnitude of extreme weather events comparable to the summer flood of 1968 (Duffey \& Mason, 1970), and those of spring 1998 (Nicholls \& Pullin, 2000) - are set to increase over the coming decades. Among the forecasts, set out in a recent review highlighting the potential effects of climate change in the UK, are projected increases in precipitation of $5 \%$ by the year 2020 and $10 \%$ by 2050 (Department of the Environment, 1996). Taken in conjunction with the continual rise in relative sea levels (George, 1992), it would appear likely that the low-lying valley fens of Broadland are destined to become increasingly flood-prone. Accommodating projected climatic change will unquestionably constitute an important element in any long-term conservation strategy drawn up for $L$. dispar. Any future trend towards wetter, warmer winters in the Northern Hemi- 
sphere might not only seriously undermine continuing attempts to re-establish the butterfly in the UK, but could equally imperil the extant native population in the Netherlands. This underlines the current emphasis being attached to a "landscape scale" approach to L. dispar restoration (Pullin, 1997). The establishment of multiple, spatially-dispersed populations, in providing potential "flood refugia" for hibernating larvae, and thereby offsetting the likelihood of catastrophic localized extinction, will lie at the core of this approach.

ACKNOWLEDGEMENTS. This research was conducted as part of English Nature's Species Recovery Programme Grants Scheme $(03 / \mathrm{GNT} / 202)$ and we are grateful for their financial assistance. Thanks also to Rick Southwood (English Nature) and Rob Andrews (Broads Authority) for assistance at field sites. CNN conducted these experiments whilst in receipt of a NERC studentship.

\section{REFERENCES}

Anon 1929: Report of the Committee appointed by the Entomological Society of London for the Protection of British Lepidoptera. Proc. Entomol. Soc. London 4: 53-68.

AYalA F.J. 1965: Evolution of fitness in experimental populations of Drosophila serrata. Science 150: 903-905.

Briscoe D.A., Malpica J.M., Robertson A., Smith G.J. \& FRANKHAM R. 1992: Loss of genetic variation in large laboratory populations of Drosophila flies: implications for the genetic management of captive populations. Conserv. Biol. 6 : $416-425$.

Broads Authority 1997: The Fenland Management Strategy: a strategy for environmentally sustainable management of the Broadland fens. Prepared by S. Tolhurst for the Broads Authority and English Nature. Broads Authority, Norwich.

ChrpPendale G.M. 1982: Insect diapause, the seasonal synchronization of life-cycles, and management strategies. Entomol. Exp. Appl. 31: 24-35.

Danks H.V. 1987: Insect Dormancy: An Ecological Perspective. Biological Survey of Canada (Terrestrial arthropods) Monograph series, 1.

Department of Environment 1996: Review of the potential effects of climate change in the UK. $2^{\text {nd }}$ report. Department of Environment, London.

DUFFEY E. 1968: Ecological studies on the Large Copper butterfly, Lycaena dispar batavus, at Woodwalton Fen National Nature Reserve. J. Appl. Ecol. 5: 69-96.

DUFFEY E. 1971: The management of Woodwalton Fen: a multidisciplinary approach. In: Duffey E. \& Watt A.S. (eds). The Scientific Management of Animal and Plant Communities for Conservation. Blackwell Scientific Publishing, Oxford.

Duffey E. 1977: The re-establishment of the Large Copper butterfly, Lycaena dispar batavus, on Woodwalton Fen National Nature Reserve. Biol. Conserv. 12: 143-158.

Duffey E. \& Mason G. 1970: Some of the effects of summer floods on Woodwalton Fen in 1968/9. Entomol. Gaz. 21 23-26.

Eutr E.A. 1951: The introduction of the large copper butterfly (Lycaena dispar batavus Oberthur) at Wheatfen Broad, Norfolk. Trans. Norfolk Norwich Nat. Soc. 17: 84-90.

Elur E.A. 1965: The Broads. Collins New Naturalist Series, London.

Finney D.J. 1971: Probit Analysis, $3^{\text {rd }}$ edition. Cambridge University Press, Cambridge.

Fowler J. \& Cohen L. 1990: Practical Statistics for Field Biology. John Wiley \& Sons, Chichester.
Frankham R. 1995: Conservation genetics. Annu. Rev. Gen. 29: 305-327.

FrankHAM R. \& Loebel D.A. 1992: Modelling conservation genetics problems using captive Drosophila populations: rapid adaptation to captivity. Zoo Biol. 11: 333-342.

George M. 1992: The Land Use, Ecology and Conservation of Broadland. Packard Publishing, Chichester.

Giller K.E. \& Wheeler B.D. 1986: Past peat cutting and present vegetation patterns in an undrained fen in the Norfolk Broadland. J. Ecol. 74: 219-247.

IRWIN A.G. 1984: The Large Copper, Lycaena dispar dispar, in the Norfolk Broads. Entomol. Rec. J. Var. 96: 212-213.

InTERNATIONAL UNION FOR tHe CONSERVATION OF NATURe 1990: The IUCN Red List of Threatened Animals. Gland, Switzerland: IUCN.

Joy J. \& Pullin A.S. 1997: The effects of flooding on the survival and behaviour of overwintering large heath butterfly Coenonympha tullia larvae. Biol. Conserv. 82: 61-66.

Joy J. \& Pullin A.S. 1999: Field studies on flooding and survival of overwintering large heath butterfly Coenonymha tullia larvae on Fenn's and Whixall Mosses in Shrophire and Wrexham, U.K. Ecol. Entomol. 24: 426-431.

LATTER B.D.H. \& MulLey J.C. 1995: Genetic adaptation to captivity and inbreeding depression in small laboratory populations of Drosophila melanogaster. Genetics 139: 255-266.

LeJeune R.R. \& Fiturk B. 1947: The effects of water level upon larch sawfly populations. Can. Entomol. 79: 155-160.

Lejeune R.R., Fell W.H. \& BurbidGe D.P. 1955: The effects of floooding on development and survival of the Larch sawfly Pristiphora erichsonii (Tenthredinidae). Ecology 36: 63-70.

LewIs O.T. \& Thomas C.D. 2001: Adaptation to captivity in the butterfly Pieris brassicae (L.) and the implications for ex situ conservation. J. Insect Conserv. 5: 55-63.

Mryatake T. \& YAMAGISHI M. 1999: Rapid evolution of larval development time during mass rearing in the melon fly, Bactrocera cucurbitae. Res. Popul. Ecol. 41: 291-297.

Nicholls C. N. 2000: Restoration Ecology of the Large Copper Butterfly Lycaena dispar. PhD. Thesis. University of Birmingham, UK.

Nicholls C.N. \& Pulcin A.S. 2000: Larval survival in wild and introduced populations of the large copper butterfly, Lycaena dispar batavus. Biol. Conserv. 93: 349-358.

Oostermeiser J.G.B. 1996: Actieplan Grote Vuurvlinder: Maatregelen voor Behoud en Uitbreiding. Report No. VS 96.27. De Vlinderstichting, Wageningen.

Pullin A.S. 1997: Habitat requirements of Lycaena dispar batavus and implications for re-establishment in England. $J$. Insect Conserv. 1: 177-185.

Pullin A.S., Balint Z., Balletto E., Buszko J., Coutsis J.G., Goffart P., Kulfan M., Lhonore J.E., Settele J. \& Van der MAde J.G. 1998: The status, ecology and conservation of Lycaena dispar (Lycaenidae: Lycaenini) in Europe. Nota Lepid. 21: 94-100.

Pullin A.S., McLean I.F.G. \& Webi M.R. 1995: Ecology and conservation of Lycaena dispar - British and European perspectives. In: Pullin A.S. (ed.). Ecology and Conservation of Butterflies. Chapman \& Hall, London, pp. 150-164.

Purefoy E.B. 1929: Chrysophanus dispar batavus Oberthur at Woodwalton Fen : Some results of submergence experiments. Proc. Entomol. Soc. London 2: 84-86.

RILEY N.D. 1929: The re-establishment of the Large Copper Butterfly in England. Nat. Hist. Mag. 11: 113-118.

Tauber M.J. \& TAưber C.A. 1976: Insect seasonality - Diapause maintenance, termination and post-diapause development. Annu. Rev. Entomol. 21: 81-107. 
Tauber M.J., Tauber C.A. \& Masaki S. 1986: Seasonal Adaptations of Insects. Oxford University Press. Oxford.

TAX M.H. 1989: Atlas van de Nederlandse Dagvlinders. De Vlinderstichting. Wageningen and Natuurmonumenten. S' Graveland.

TinnING P.C. 1975: Some observations on the overwintering larvae of the Large Copper butterfly, Lycaena dispar batavus (Oberthur), at Woodwalton Fen National Nature Reserve. Entomol. Gaz. 26: 2490150252.

WebB M.R. \& Pullin A.S. 1996: History of establishment attempts with the Large Copper butterfly, Lycaena dispar. Entomol. Rec. J. Var. 108: 321- 328 .
Webb M.R. \& Pullin A.S. 1998: Effects of submergence by winter flooding on diapausing caterpillars of a wetland butterfly, Lycaena dispar batavus. Ecol. Entomol. 23: 96-99.

WebB M.R. \& Pullin A.S. 2000: Egg distribution in the large copper butterfly Lycaena dispar batavus (Lepidoptera: Lycaenidae): host plant versus habitat mediated effects. Eur. J. Entomol. 97: 363-367.

WheEler B.D. 1978: The wetland plant communities of the River Ant Valley, Norfolk. Trans. Norfolk Norwich Nat. Soc. 24: 153-187.

Worwod I.P. 1997: Detecting the effects of climate change on Lepidoptera. J. Insect Conserv. 1: 149-158.

Received September 10, 2001; revised May 17, 2002; accepted June 10, 2002 